\title{
American Pediatric Society's 2008 John Howland Award Acceptance Lecture: Life Goals for Academic Pediatrics
}

\author{
RICHARD B. JOHNSTON, JR.
}

Department of Pediatrics, University of Colorado Denver School of Medicine and National Jewish Medical and Research Center, Denver, Colorado 80262

$\mathrm{W}$ hat makes the John Howland Medal such a meaningful honor to a new recipient, at least certainly to me, is the list of the previous awardees. Because improving the lives of children has been (and remains) the central goal of my professional life, no other recognition could be as meaningful to me; and I am deeply grateful to the American Pediatric Society (APS) for selecting me.

One of the benefits of this special honor is the opportunity to thank publicly those who have been important to my life and career. I want to start by thanking Larry Boxer, for believing I might be a reasonable candidate and for the extraordinary kindness reflected in the time and thought that he devoted to the nomination and his presentation this morning. Thanks, Larry, for this most meaningful of all gifts.

I also want to thank those who, along the way, indicated through words or actions that they thought I could do the job at hand, at times when I was not sure of that myself. These include six earlier recipients of this award: Amos Christie, Millie Stahlman, Floyd Denny, David Nathan, Bill Nelson, and Fred Battaglia. In more recent years, this group includes Bill Benton at Alabama, Jennifer Howse, President of the March of Dimes, Joe Warshaw at Yale, and my pediatrician Dean, Dick Krugman.

This platform is also an opportunity to thank the many of you with whom I have worked over the years to improve the health of children. Outside of my family, no other group has been more important to me than my friends in pediatrics.

At this point, I probably should sit down, having expressed the appreciation that I feel so strongly for those who shaped my professional life. This would be in full agreement with a central precept of my career based on advice from Mark Twain: "Better to remain silent and appear ignorant than to open your mouth and remove all doubt" (1).

On the other hand, this is the third $(2,3)$, and last, chance you in the Pediatric Academic Societies (PAS) will give me to deliver a plenary address (however brief) at this annual meeting; and I have some parting thoughts that I would like to share.

To begin with, I hope you will forgive me if I extol to you, the choir, the joy and fulfillment that I have felt in being a

Received May 28, 2008; accepted May 30, 2008.

Correspondence: Richard B. Johnston, Jr., M.D., Office of the Dean, C290, University of Colorado Denver School of Medicine, 4200 East Ninth Avenue, Denver, CO 80262; e-mail: richard.johnston@uchsc.edu

Presented at the 2008 Annual Meeting of the Pediatric Academic Societies, Honolulu, Hawaii. pediatrician. Except for picking Mary Anne to be my wife, choosing pediatrics was the smartest decision I ever made.

As a start, no medical discipline comes close to ours in its ability to influence our patients' health and emotional wellbeing across an entire life span.

The benefits of our influence are achieved most commonly, of course, through the mother. When I decided on pediatrics in my senior year, I was influenced by the lifelong impact on my mother of a practicing pediatrician, Dr. Tefft. My mother was a young, sensitive woman from the south trying to raise three young sons in cold Boston, while my father traveled. What Dr. Tefft gave my mother was immeasurably important to her and her sons, guidance in child-raising and confidence that she was, in fact, a good mother.

I experienced the fulfillment of giving this sort of support when I was a pediatrician in the military. The mothers in my Thursday well-baby clinic were usually overworked and often stressed about some variation in normal infant physiology or development. As you would know, what was needed most of the time was a little advice and lots of praise for raising a beautiful baby. What a wonderful way to make a living!

What a privilege to be able to help a sick child! Children are not interested in being sick. And what clientele can be more fun to work with than children? Pediatrics is a chance to use your sense of humor with an audience at about your same level of wit and sophistication.

Those of us in academic pediatrics can work toward improving the lives of children in additional ways. Teaching the principles of quality of care that we believe in and doing research are obvious examples. But we also place ourselves in a position to change policy related to child health and to work toward the day that our political process assigns children a value commensurate with the fact that they will determine our future. In sum, whether in practice or academic pediatrics, we share the world's happiest profession, and we work to help the world's most important population, its children.

That brings me to the academic pediatric societies. A recent study in the Archives of General Psychiatry showed that conscientious people were $89 \%$ less likely to develop Alzheimer's disease over a $12-y$ period (4). This was somewhat reassuring to me, as it should be to most pediatricians. In this study, cognitive decline was slowed in older individuals who had definite "life goals." This was also nice to hear because I still have a long list of these. 
Table 1. Major challenges in pediatrics as potential goals for the pediatric academic societies

Birth defects and prematurity-leading causes of infant mortality Infection-leading cause of childhood deaths worldwide Prevention-especially accidents and preconditions to adult disease Development of clinical investigators-fix the broken pipeline The undervaluing of children

Education-fundamental to health and the future of our society Vaccine efficacy, safety, parental acceptance

So how does this relate to our academic societies? It seems to me that this same principle holds for aging organizations. The APS is 120 y old this year! The Society for Pediatric Research (SPR) will be 79 and the Academy 78. The impressive energy and innovation of the Academic Pediatric Association reflect its relative youth, 48 this year; and our esteemed new partner, the Asian SPR, is a 3-y-old infant. So what are the specific life goals of our central academic societies? It seems to me critically important that these societies also have goals to avoid senility.

I would never presume to undertake strategic planning for the APS, SPR, and Academic Pediatric Association, whose membership consists of our most capable and motivated academicians. But we are faced with enormous challenges to the wellbeing of children, and I would like to suggest examples of major issues, around which goals might be framed (Table 1).

- Obviously, prematurity and birth defects, by far the leading causes of infant mortality (5). Think of how much information could be gained on these disorders from linked universal electronic obstetrical and neonatal medical records tied to genetic analysis.

- Infection - the leading cause of childhood deaths worldwide (6). New research in my field of immunology has led to a shift in paradigm: the inflammatory response, not the organism, is now recognized as the threat to survival $(7,8)$. In my opinion, the central challenge now to infection research is to discover how to enhance the immune response while containing the cytokine storm.

- Prevention-We still need much more effective approaches to preventing accidents and preconditions to adult disease.

- The "broken pipeline" for development of clinical investigators needs a long-lasting fix.

- Undervaluing children-a broad target with many expressions, most commonly inadequate funding. What data are available to explain this phenomenon? Is it possible that an evidence-based analysis-of-causes could direct our efforts to correct this most tragic of American political blunders?

- Education-Is this an issue for pediatricians? I think so, and it's one that I would like to understand better. Recent analyses suggest that the single factor predicting longevity is not diet, exercise, smoking, or the like, but, rather, the number of years spent in school (9). But education means more than just better health; it prepares the child for a richer, more secure adulthood, and it prepares the country for a more enlightened future. Funding is the challenge; but to quote Derek Bok, "If you think education is expensive, try ignorance" (10).
- Lastly, vaccine efficacy, safety, and parental acceptance need persistent attention.

So how could the academic pediatric societies address goals based on issues like these? It seems to me that the mechanism is already in place in the form of this consistently outstanding annual meeting. Construct the program on the best science and continue to frame it to attract bench and clinical researchers, practitioners, and our academic leaders and promote their interaction. But start the planning each year with additional council time devoted only to asking how the meeting can be used to address the really big issues related to children.

And then determine how you can involve the broad membership in solving these issues within and outside the meeting. We experimented along these lines once in the APS with at least some success: more participation in advocacy, consecutive PAS workshops on developing leadership, guidelines for support of young investigators published in Pediatric Research, and a history of pediatric subspecialties $(3,11,12)$. Each Council may need a member elected to serve specifically as program chair, to provide the continuity and extra effort that will be needed.

To conclude: Members of the PAS represent the elite of our discipline, and the societies allow concerted action. But without clear goals, the societies risk senility. We have the potential to lead the country toward resolution of the major issues in pediatrics and to a better life for its children. We have this opportunity because we are pediatricians.

Now, one last thank-you: What has sustained me for the last 48 y has been the support of my wife Mary Anne. Mary

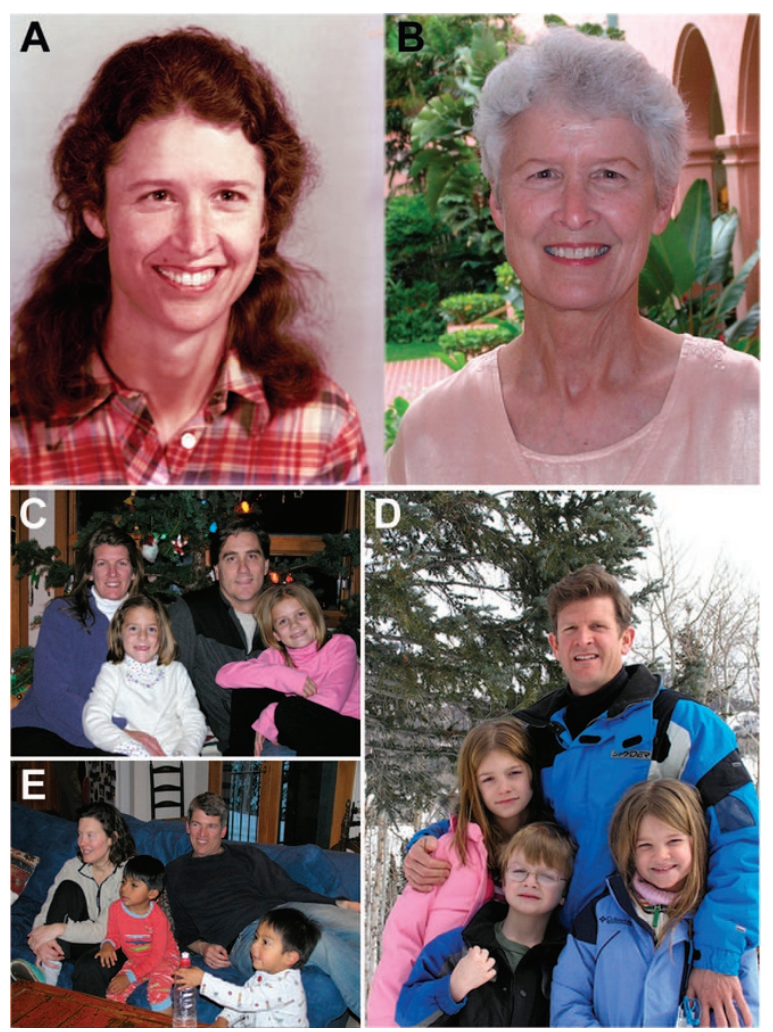

Figure 1. A, Mary Anne Johnston, 1970 and B, 2008. $C$, left to right: Kristin, Isabelle, Jason, Serena Rusk; $D$, clockwise from top: Richard III, Keillor, Richard, Annelise Johnston; E, left to right: Clarissa, Teo, Claiborne, Nico Johnston. 
Anne's complete commitment to our children and me allowed me to maintain a commitment to my professional life goals. Without her commitment, achieving my goals would have been impossible (Fig. $1 A$ and $B$ ). As you can see, she has lost nothing in these $48 \mathrm{y}$ except her brown hair. In exchange, we have gained three children (Fig. $1 C-E$ ), of whom I am enormously proud, two exceptionally fine spouses, and seven grandchildren, who have inspired and charmed me and excited my hopes for a better world.

Acknowledgments. W. Dillon Johnston, Ph.D., gave constructive comments that improved the manuscript. Douglas Kamerow, M.D. and Adriana Lleras-Muney, Ph.D. supplied information relating education to longevity. Barry M. Silverstein created the figure.

\section{REFERENCES}

1. Sherrin N (ed) 1995 A Dictionary of Humorous Quotations. New York: Oxford University Press Inc, p 129 (attributed to Twain in various wordings)
2. Johnston RB Jr 1981 The impact of research in pediatrics on the health of children (Society for Pediatric Research presidential address). Pediatr Res 15:1465-1467

3. Johnston RB Jr 1997 The ever-whirling wheel of change: American Pediatric Society presidential address 1997. Pediatr Res 42:909-912

4. Wilson RS, Schneider JA, Arnold SE, Bienias JL, Bennett DA 2007 Conscientiousness and the incidence of Alzheimer disease and mild cognitive impairment. Arch Gen Psychiatry 64:1204-1212

5. National Center for Health Statistics Period Linked Birth/Infant Death Data, 2004 Available at: www.marchofdimes.com/peristats. Accessed May 2, 2008

6. WHO World Health Statistics 2008 Mortality and Burden of Disease. Available at: http://www.who.int/whosis/whostat/EN_WHS08_Table1_Mort.pdf. Accessed May 2, 2008

7. Barton GM 2008 A calculated response: control of inflammation by the innate immune system. J Clin Invest 118:413-420

8. Finch CE, Crimmins EM 2004 Inflammatory exposure and historical changes in human life-spans. Science 305:1736-1739

9. Cutler D, Deaton A, Lleras-Muney A 2006 The determinants of mortality. J Econ Perspect 20:97-120

10. Shapiro FR (ed) 2006 The Yale Book of Quotations. New Haven: Yale University Press, p 93

11. Jobe AH, Abramson JS, Batshaw M, Boxer LA, Lister G, McCabe E, Johnston R 2002 Recruitment and development of academic pediatricians: departmental commitments to promote success. Pediatr Res 51:662-664

12. Finberg L, Stiehm ER (eds) 2006 The American Pediatric Society History of Pediatric Subspecialties. Baltimore: Wolters Kluwer/Lippincott Williams \& Wilkins 